\title{
Design and Evaluation of a Polarizer Filter
}

\author{
Duaa muthana \\ Abdullah Ibrahim Abbo Al-Numan
}

Received 28/3/2018, Accepted 2/9/2018, Published 13/9/2018

This work is licensed under a Creative Commons Attribution 4.0 International License.

\begin{abstract}
:
This research includes theoretical and evaluation design of a polarizer filter of high transmission in the near IR region of (900-1200nm) for different incidence angles to obtain a long wave and short wave pass filter using analytical calculations. Results refer to a new configuration design in fewer layers than used in previous studies in the long wave pass at incidence angles $\left(45^{\circ}, 50^{\circ}, 55^{\circ}\right)$. Adopted Hafnium dioxide ( $\left.\mathrm{HfO} 2\right)$ and Magnesium fluoride (MgF2) as coating material at design wavelength (933nm), the study also included design short wave pass polarizer by using the same coating material.
\end{abstract}

Keywords: Characteristics Matrix, long-pass wave, optical interference filter, polarizer filters, short-pass wave.

\section{Introduction:}

Optical filters now adays play a significant role in technology and communications and its known as a tool that rejects specific wavelengths and it has wide applications of electromagnetic spectrum extending from the Ultraviolet to the IRregion(1) .A multilayer filter can be constructed by a number of thin-films deposited on a substrate by different coating methods. The multilayer filter has the property of being able to reflect some wavelengths and transmit others depending on the relative constructive and destructive interference between transmitted and reflected light rays. Different applications exist for interference filters including reflectors, anti-reflection coatings and polarizers $(2,3)$.A filter that transmits a single state of polarization of light while absorbing, reflecting or deviating the rest of the other polarization states is known as polarizer. When the state of polarization is orthogonal to the wave with the electric vector in the plane of incidence is known as p-polarized or, sometimes, as TM (for transverse magnetic), and a wave with the electric vector normal to the plane of incidence called s-polarized or, sometimes, TE (for transverse electric).

Polarizer filter has many applications such as fluorescence polarization arrays and imaging, second-harmonic-generation imaging and laser materials processing, telephoto lenses, prescription glasses, digital cameras, optoelectronics, and spectroscopes filtration technologies $(4,5,6,7)$.

Department of Physics, College of Science for Women, University of Baghdad, Baghdad, Iraq.

*Corresponding author: dralaanazar@yahoo.com
The concept of a filter is based on interference within a dielectric optical multilayer deposited on a substrate. Important benefits are found in the optical polarizer including superior transmission, low scattering, and very little wave front distortion, and controllable bandwidth.

The optical polarizer is based on the phenomenon known as polarization splitting (8). The plane of incidence is known as that plane containing the normal to the coated surface and the incident ray direction. This plane also has reflected and transmitted ray directions (8).in this paper optical performance of polarizer filter of (LWP) and (SWP) were performed and study depends on the characteristic matrix of thin film layers, adopted Hafnium dioxide $\left(\mathrm{HfO}_{2}\right)$ and Magnesium fluoride $\left(\mathrm{MgF}_{2}\right)(9,10)$ as high and low refractive index material respectively deposited on glass substrate of index of refraction 1.52

\section{Theoretical approach:}

The state of polarization of electromagnetic (EM) radiation can be expressed by the characteristic matrix of the thin film.The characteristic matrix of thin film layers is simply the product of individual matrices for the individual layers of the assembly taken in the correct order, which is given by

$$
\left[\begin{array}{l}
\mathrm{C} \\
\mathrm{B}
\end{array}\right]=\left(\prod_{\mathrm{r}=1}^{\mathrm{q}}\left[\begin{array}{cc}
\cos \delta_{\mathrm{r}} & \left(\mathrm{in} \delta_{\mathrm{r}}\right) / \mathrm{n}_{\mathrm{r}} \\
\mathrm{in}_{\mathrm{r}} \sin \delta_{\mathrm{r}} & \cos \delta_{\mathrm{r}}
\end{array}\right]\left[\begin{array}{l}
1 \\
\mathrm{n}_{\mathrm{s}}
\end{array}\right]\right) \ldots \ldots 1
$$

where $\mathrm{C}$ and $\mathrm{B}$ are normalized totals tangential electric and magnetic fields respectively at input surface. 
$\delta \mathrm{r}=2 \pi \mathrm{n}_{\mathrm{r}} \mathrm{d}_{\mathrm{r}} / \lambda_{\mathrm{o}} \ldots . .2$

$\delta r$ is the phase thickness, $\lambda_{o}$ is the design wavelength and $\mathrm{dr}$ and $\mathrm{n}$ are the physical thickness of layers and the refractive index respectively.(11)

For $s$ polarization, the refractive index is given by the effective index

$\eta_{s}=n \cos \theta \ldots .3$

$\eta \mathrm{s}$ is the effective indexfor s- state, $n$ is the index of refraction and $\theta$ is the angle of incidence.

For $p$ polarization, effective index $\eta_{p}$ also is given by refractive index

$\eta_{p}=n / \cos \theta \ldots .4$

The phase thickness of the thin film, in both cases, is multiplied by $\cos \theta$ thus, the effective phase thicknesses are given by(11)

$\delta_{\mathrm{s}}=\left(2 \pi / \lambda_{\mathrm{o}}\right) \mathrm{n} d_{s} \cos \theta_{\mathrm{s}} \ldots .5$

$\delta_{\mathrm{p}}=\left(2 \pi / \lambda_{\mathrm{o}}\right) \mathrm{n} d_{p} \cos \theta_{\mathrm{p}} \ldots .6$

The characteristic matrix is modified to a new form for $\mathrm{s}$ and $\mathrm{p}$ polarizations as follows:

$$
\begin{aligned}
& {\left[\begin{array}{cc}
\cos \delta_{\mathrm{s}} & \left(\mathrm{i} / \eta_{\mathrm{s}}\right) \sin \delta_{\mathrm{s}} \\
\left(\mathrm{i} \eta_{\mathrm{s}}\right) \sin \delta_{\mathrm{s}} & \cos \delta_{\mathrm{s}}
\end{array}\right] \ldots .7} \\
& {\left[\begin{array}{cc}
\cos \delta_{\mathrm{p}} & \left(\mathrm{i} / \eta_{\mathrm{p}}\right) \sin \delta_{\mathrm{p}} \\
\left(\mathrm{i} \eta_{\mathrm{p}}\right) \sin \delta_{\mathrm{p}} & \cos \delta_{\mathrm{p}}
\end{array}\right] \ldots .8}
\end{aligned}
$$

Thus the transmittance of the multilayer system in the oblique incident for $s$ and $p$ is given by:

$$
\mathrm{T}=\frac{4 \mathrm{n}_{\mathrm{o}} \operatorname{Re}\left(\mathrm{n}_{\mathrm{s}}\right)}{\left(\mathrm{n}_{\mathrm{o}} \mathrm{B}+\mathrm{C}\right)\left(\mathrm{n}_{\mathrm{o}} \mathrm{B}-\mathrm{C}\right)} \ldots . .9
$$

\section{Experimental Demonstration:}

In this work, we apply approach depends on the characteristic matrix to design polarizer filters of long-wave pass and short-wave pass, for near infrared region (900-1200nm) with utilize glass as substrate and adopted $\left(\mathrm{HfO}_{2}\right)$ as a high refractive index material and $\left(\mathrm{MgF}_{2}\right)$ as a low refractive index material .

The design of optical polarizer depends on its construction stacks and selected materials, construction involves deposition of a number of thin layers of high and low refractive index on a base substrate according to a specific stack configuration.

The substrate is glass of refractive index 1.52 coated by $\mathrm{HfO}_{2}$ of a high refractive index $\left(\mathrm{n}_{\mathrm{H}}=1.98\right)$ and $\mathrm{MgF}_{2}$ of a low refractive $\operatorname{index}\left(\mathrm{n}_{\mathrm{L}}=\right.$ 1.38)sequentially.

\section{Result and Discussion:}

The stack configuration of design (LWP) polarizer are (12):

Air | $\left(0.5 \mathrm{H}^{\prime} \mathrm{L}^{\prime} 0.5 \mathrm{H}^{\prime}\right)^{\wedge^{3}}\left(0.5 \mathrm{H}^{\prime \prime} \mathrm{L}^{\prime \prime} 0.5 \mathrm{H}^{\prime \prime}\right)^{\wedge^{8}}\left(0.5 \mathrm{H}^{\prime} \mathrm{L}^{\prime}\right.$

$$
\left.0.5 \mathrm{H}^{\prime}\right)^{\wedge} \mid \text { Glass }
$$

And $H^{\prime}=1.010 H, L^{\prime}=1.146 L, H^{\prime \prime}=1.076 H$, and $L^{\prime \prime}=$ $1.220 L$ with $\lambda_{o}=933 \mathrm{~nm}$, Where $\mathrm{L}$ represents the low quarter wave of optical thickness and $\mathrm{H}$ represent the high quarter wave of optical thickness.

The transmission has been calculated according to the effects of the incident angles for the materials using equations (9), as illustrated in fig(1), it appears no obvious effects showing of the optical performance of the polarizer at the incidence angles $\left(\theta=5^{\circ}, 10^{\circ}, 15^{\circ}, 20^{\circ}\right)$.

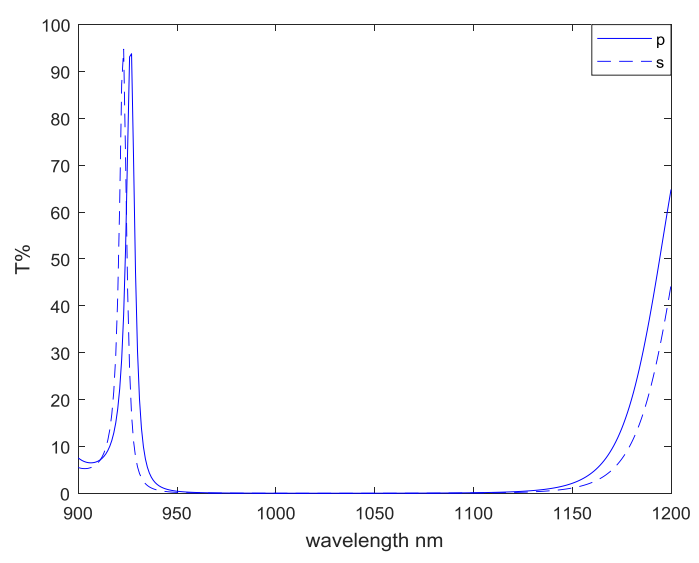

Figure1. Optical performance of polarizer at incidence angles $\left(\theta=5^{\circ}, 10^{\circ}, 1^{\circ}, 20^{\circ}\right)$

In increasing the value of incidence angles, lines of $\mathrm{p}$ and s polarization begin to be clarified at $\left(\theta=25^{\circ}, 30^{\circ}, 35^{\circ}\right.$ and $\left.40^{\circ}\right)$. and the separation between two states of polarization clearly starts at $\left(\theta=35^{\circ}, 40^{\circ}\right)$ and it can be considered that at angles of incidence $\left(\theta=45^{\circ}, 50^{\circ}, 55^{\circ}, 60^{\circ}\right)$ achieved an optical performance of polarizer filter as illustrated in the figs $(2 \mathrm{a} \& 2 \mathrm{~b})$.

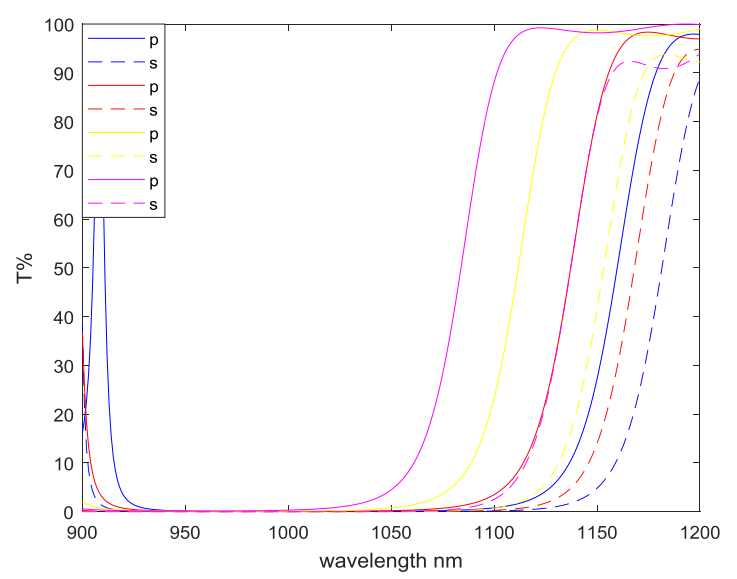

Figure 2.a Optical performance of polarizer at incidence angle $\left(\theta=25^{\circ}, 30^{\circ}, 35^{\circ}, 40^{\circ}\right)$ 


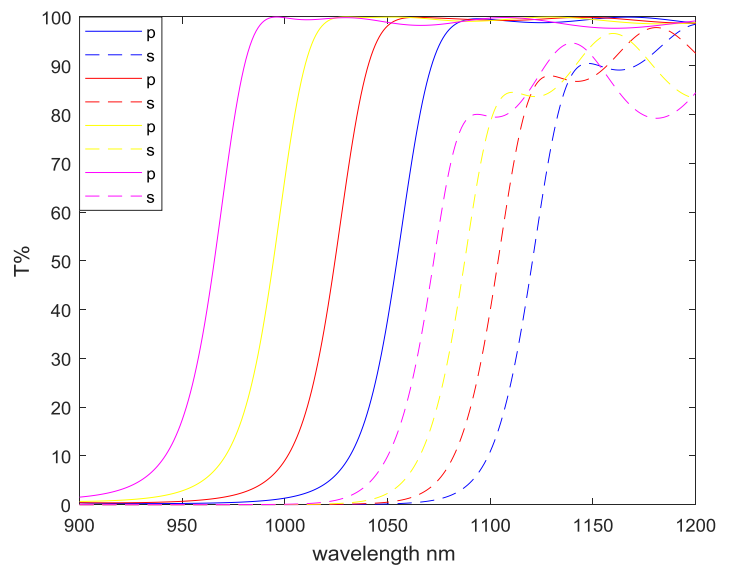

Figure 2.b Optical performance of polarizer at incidence angle $\left(\theta=4^{\circ}, 50^{\circ}, 5^{\circ}, 60^{\circ}\right)$

The results refers that there is a shift toward the shorter wavelengths of the electromagnetic spectrum with increasing of incident angle, and it's more obvious at $\left(\theta=65^{\circ}, 70^{\circ}\right)$ as shown in fig( $(3)$.

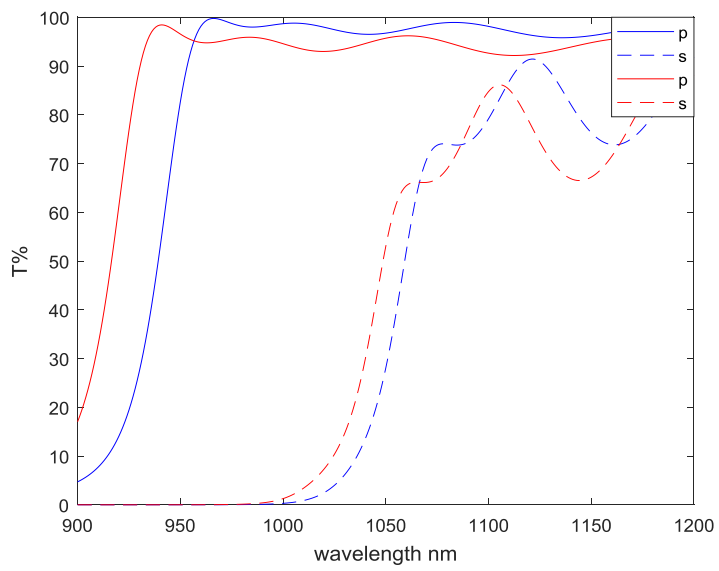

Figure 3. Optical performance of polarizer at incidence angle $\left(\theta=65^{\circ}, 70^{\circ}\right)$

Thus we find that the characteristics of the optical coating vary with the incidence angle, so the shifting towards the shorter wave lengths is the main observed effect, more than $\left(\theta=70^{\circ}\right)$ we were an able to achieve an optical performance of the polarizer because one of the polarization modes $(p$ mode) out of range due to the shifting that occurs towards shorter wavelength.

Figure 4 shows design of polarizer filter with fewer number of coating layers by reduction the order of stack at incident angles $\left(\theta=45^{\circ}\right.$, $\left.50^{\circ}, 55^{\circ}\right)$, by using the same coating martial.

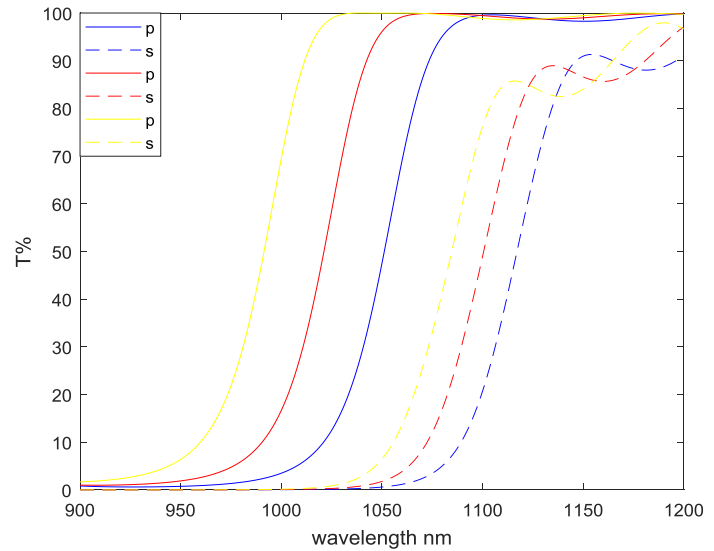

Figure4. The Optical performance polarizer at incidence angle $\left(\theta=\mathbf{4 5}^{\circ}, \mathbf{5 0}^{\circ}, 5^{\circ}\right)$ using stacks:

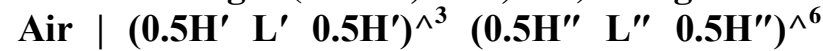
$\left(0.5 H^{\prime} L^{\prime} 0.5 H^{\prime}\right)^{\wedge}{ }^{3} \mid$ Glass[16]

We see that by using only 30 number of coating layer we were able to get an optical performance of polarizer filter with high transmission in the pass band without occurrence ripples, this result is very important to overcome manufacturing problems.

Now in this part we intend to changing the stack formula in order to design an interference filter in the short pass wave at the incidence angle $\left(\theta=50^{\circ}\right)$, with designed wavelength at $\lambda_{0}=1064 \mathrm{~nm}$ by using the same coating materials were previously used as illustrated in figs ( $5 a \& 5 b$ ).

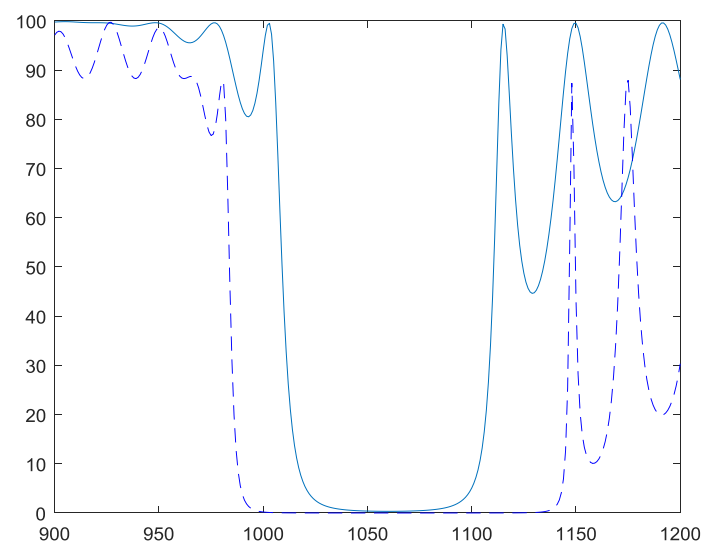

Figure 5a. Optical performance of polarizer at an incidence angle $\left(\theta=50^{\circ}\right)$ at wavelength design $1064 \mathrm{~nm}$ using stack $n_{0}[\text { L1.7 H L }]^{\wedge 14} n_{S}$ 


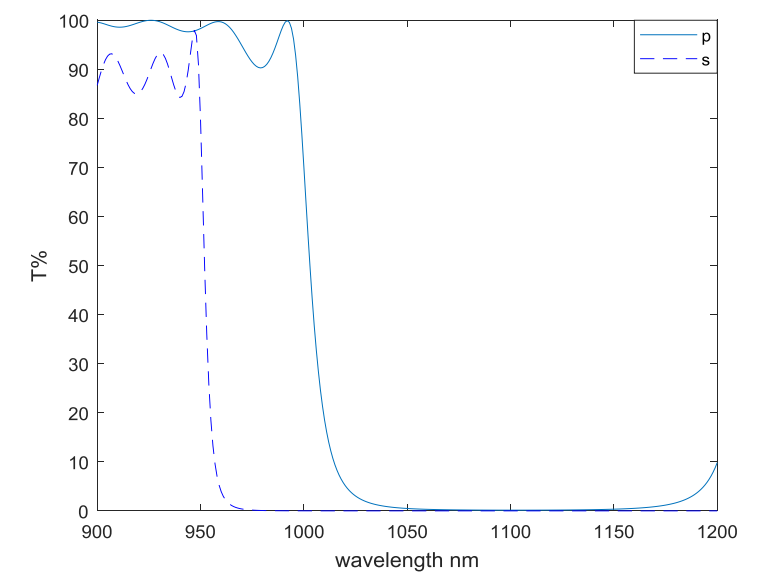

Figure 5b. Optical performance of polarizer at an incidence angle $\left(\theta=50^{\circ}\right)$ at wavelength design $1064 \mathrm{~nm}$ using stack $0.7945504 \mathrm{H} 0.93769344 \mathrm{~L}$ 0.9662688H 0.9291632L 0.8393224H 0.8647632L $\begin{array}{lll}0.821912 \mathrm{H} & \mathbf{0 . 8 6 6 4 9 6 4 8 L} & \mathbf{0 . 8 3 8 3 8 7 2 H}\end{array}$ $\begin{array}{lll}0.88035536 L & 0.8602832 \mathrm{H} & \mathbf{0 . 8 5 8 2 1 6 4 8 L}\end{array}$ $\begin{array}{llll}0.8470336 H & 0.12804192 L & 0.826168 H\end{array}$ $\begin{array}{lllll}0.85097056 & 0.824656 H & 0.5451 L & 1.3017144 H\end{array}$ $\begin{array}{lll}0.55837744 \mathrm{~L} & \mathbf{1 . 4 5 3 9 3 3 6 H} & \mathbf{0 . 3 0 7 5 7 4 4 L}\end{array}$ $\begin{array}{lll}1.7784928 H & 0.60333968 H & 1.6246048 L\end{array}$ $\mathbf{0 . 3 7 6 9 5 7 1 2 H}$

Fig (5a) represent design of short wave polarizer filter using quarter wave stack for 42 number of coating layers we notice narrow separation between the two state of polarization with being ripples in the both pass and stop band while figure $5 \mathrm{~b}$ represent submitted new construction stacks for optimal design of short wave polarizer by using non-quarter wave stack for fewer number of layer with the observation of no ripples occurs in the stop band.

\section{Conclusions:}

An Optical polarizer filter in the near IR (900-1200nm) has been designed for oblique incidence for both short and long wavelengths. The optical performance clarifies shifting towards shorter wavelength as the incidence angle increase. The analytical method gave us the possibility to decreasing the number of layers of the stacks while keeping at the same time good performance of the polarizer filter at angle of incident $\left(\theta=45^{\circ}, 50^{\circ}\right.$, $55^{\circ}$ ) also the work included a short wave pass design using non-quarter stack at $\left(\theta=50^{\circ}\right)$ at reference wavelength $1064 \mathrm{~nm}$ with fewer number of coating layers.

\section{Conflicts of Interest: None.}

\section{References:}

1. Basu PK. Theory of optical processes in semiconductors: bulk and microstructures. Clarendon press. 1997; (4): 90.

2. Chandran A. Self-assembled multilayered dielectric spectral filters M.Sc. Thesis Virginia Polytechnic Institute and State University. 2001.

3. Nazar A. Modeling and optimum design band pass filter for mid IR region, BSJ. 2014; 11(4):1459-1466.

4. Rabady R, Ababneh A. Global optimal design of optical multilayer thin-film filters using particle swarm optimization. IJLEO. 2014;125(1).

5. Dobrowolski JA. Numerical methods for optical thin films. Optics and Photonics News. 1997; 8(6):24-33.

6. GangBao, Yuliang Wang, Optimal design of antireflection coatings with different metrics. J. Opt. Soc. Am. A, 2013;30(4).

7. Abdullah GH, Mhdi B, Al. Jabar N. Design thin film narrow band pass filters for dense wavelength division multiplexing, IJAAS, 2012;1(2):65-70.

8. Lin M, Xi X, Qiu W, Ai Y, Wang Q, Liu Q, Ouyang Z. Star-type polarizer with equal-power splitting function for each polarization based on polarizationdependent defects in two-dimensional photoniccrystal waveguides. Optics Express. 2016;24(21): 23917-23924.

9. Zhao J, Zhang Y, Gong H, Zhang Y, Wang X, Guo $\mathrm{X}$, et.al. Fabrication of high-performance $\mathrm{Y} 2 \mathrm{O} 3$ stabilized hafnium dioxide refractories. Ceramics International, 2015;41(4):5232-5238.

10.Hennessy J, Jewell AD, Greer F, Lee MC, Nikzad S. Atomic layer deposition of magnesium fluoride via bis (ethylcyclopentadienyl) magnesium and anhydrous hydrogen fluoride. J Vac Sci Technol A. 2015;33(1): 01A125.

11. Nazar A and Jasem NA. Synthesis of non-polarized short-wave pass filters for three regions, ARPN. 2018; 13: 1499-1502.

12. Stenzel O. Optical Coatings: material aspects in theory and practice. Springer-Verlag 2014. 


\section{تصميم وتقييم مستقطب بصري}

عبدالله ابراهيم ابو النعمان
الاء نزار عبد الغفار

قسم الفيزياء، كليه العلوم للبنات، جامعه بغداد، بغداد، العر اق.

الخلاصة:

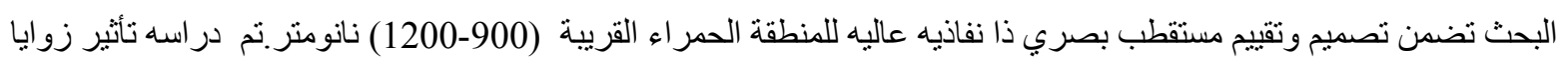

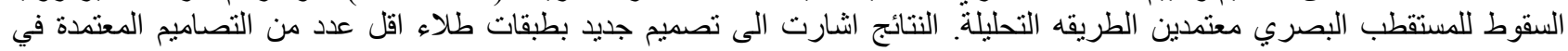

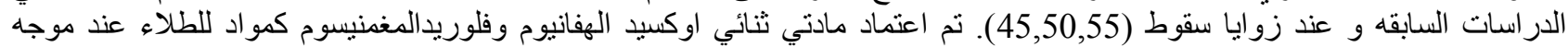

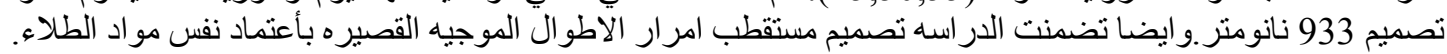

الكلمات المفتاحية: المصفوفه المميزه ، مرشحات امر ار الحزمه الطويلة،مرشحات التداخل البصري ، مستقطب بصري ،مرشح

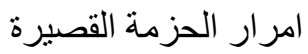

